\title{
EESTI VÄLTESÜSTEEMI OLEMUSEST
}

\author{
KARL PAJUSALU
}

$\mathrm{M}$ ati Hint on oma artikli „Kolme häälikuvälte eksituse mehaanika” (2015) ehitanud üles kriitikana minu artikli „Eesti keele sõnaprosoodia lõuna-läänemeresoome taustal" (Pajusalu 2014) kohta. Nimetatud artiklis lähtun eesti välteid liivi ja vadja keelega võrreldes kõnetakti- ehk sõnavälte kontseptsioonist. Mati Hint peab seda kontseptsiooni häälikuvälte teooria edasiarenduseks. Püüan järgnevaga näidata, et sõnavälte teooria on olemuslikult veel kaugem häälikuvälte omast kui silbivälte teooria. Pean vajalikuks kohe rõhutada, et minu ja Hindi suhtumises häälikuvälte teooriasse ning sellest tulenevatesse hädadesse põhimõttelist erinevust ei ole. Erinev on meie arusaam hääliku-, silbi- ja sõnavälte teooria suhtest. Ning ka sellest, mis on tänapäeva fonoloogia.

\section{Eesti väldete praegune uurimisseis}

Oma eelnimetatud artiklis esitan eesti keele väldete foneetilise kirjelduse, arvestades uusimaid, Tartu Ülikooli spontaanse eesti keele korpuse ainestiku akustilistel mõõtmistel põhinevaid analüüse (Lippus jt 2013) ning ka uusi vältetaju eksperimentaalsel uurimisel saadud tulemusi (nt Lippus, Pajusalu 2009; Lippus jt 2011). Minu käsitlus toetubki uutele empiirilistele uurimistulemustele, seda ka liivi keele ja eesti murrete puhul. Minu fonoloogilise lähenemise aluseks on Külli Prillopi artiklis (2013) esitatud analüüsid. See minu artiklis viidatud põhjalik fonoloogiline uurimus, mis on valminud sama teadusprojekti raames, annab ülevaate uutest fonoloogilistest käsitlustest eesti vältesüsteemi kohta ja võtab ka kokku eesti väldete olulisemad varasemad fonoloogilised tõlgendused, käsitledes samuti Hindi seisukohti.

Hint kirjutab, et „Pajusalu ülevaatlik artikkel jätab mulje, et selles on teadlikult kõrvale jäetud eesti keele prosoodia uurimise ja tõlgendamise ajajärk 1960-1990" (Hint 2015: 163). See on õige tähelepanek, minu artikli teemaks ei olnud varem esitatud eesti vältekontseptsioonide võrdlus, vaid empiiriliste uuringute praeguse seisu fikseerimine ning eesti ja lähisugulaskeelte seni vähe tähelepanu saanud sarnasuste esiletoomine. Eesti fonoloogia arenguteid olen käsitlenud teistes artiklites (nt Pajusalu 2008).

Lisaks heidab Hint korduvalt ette „tänapäeva fonoloogia” seisukohtadega mittearvestamist. Paraku Hint ei seleta, miks ta ei pea minu artiklis esitatud kõige uuemaid uurimusi eesti väldete kohta tänapäevasteks ning miks ta arvab seda oma põhiliselt 1970.-1980. aastatel formuleeritud vaadete kohta. Uusim Hindi poolt viidatud fonoloogiline artikkel on tema enda 2001. aastal ilmunud kirjutis, mis esitab suuresti ta varasemaid seisukohti. Fonoloogia tegi 1990. aastatel seoses optimaalsusteooria ja sellele tugineva fonoloogilise tüpoloogia esiletõusuga läbi olulise uuenemise, millega koos on edasi arenenud ka 
eesti fonoloogia, kirjutatud kaalukaid artikleid (vt Prillop 2013; Pajusalu 2014 kirjandus) ning kaitstud doktoritöid (nt Lippus 2011; Prillop 2011). Need uuel aastatuhandel ilmunud uurimused, mis valdavalt käsitlevad väldet kui kõnetakti omadust, on Hint jätnud kõik lihtsalt kõrvale ning eelistanud korrata aastakümnete taguseid vaateid ja neil põhinevaid arutlusi, mis olid omas ajas kahtlemata märkimisväärsed.

Viimastel aastatel on eesti väldete uurimisel toimunud märkimisväärne edasiminek nii vältetaju mehhanismide selgitamisel (vt Lippus jt 2011) kui ka väldete akustiliste korrelaatide tuvastamisel spontaanses argikõnes (vt Lippus jt 2013). Tajutestide ja akustiliste uuringute tulemused osutavad ühemõtteliselt, et eesti keele väldete tajumine ja produtseerimine toimib kõnetakti kui terviku piires. Eesti keele kolme välte vastandus on kompleksne mitmetunnuseline hääldusnähtus, kus lisaks primaarsetele kestussuhetele on olulised erinevused põhitoonis, intensiivsuses, häälikute kvaliteedis ning ka rõhulise ja järgneva rõhutu silbi seostumise viisis. Pean vältimatuks, et fonoloogilises analüüsis tuleb arvestada empiiriliste faktidega, nagu seda teevadki reeglina viimastel aastatel esitatud eesti väldete fonoloogilised käsitlused.

\section{Eesti väldete uued fonoloogilised tõlgendused}

Hindi artikli teoreetilises keskmes ei ole väitlus Karl Pajusalu, vaid Ilse Lehiste seisukohtadega. Ühtki teist minu tööd peale nimetatud 2014. aasta artikli ei ole ta käsitlenud, samas on aga refereerinud Lehiste aastatel 1960-2000 ilmunud artiklites esitatut ja püüdnud Lehiste järeldusi vaidlustada. Ehkki olen koos Lehistega kirjutanud kolm raamatut ja meil on ilmunud ühisartikleid (neist viimane Lehiste surma-aastal avaldatud Lehiste, Pajusalu 2010), ei saa ma ometi hiljuti lahkunud, läbi aegade rahvusvaheliselt kõige tunnustatuma eesti keeleteadlase eest sõna võtta. Järgnevalt esitan üksnes oma arvamusi eesti vältesüsteemi olemuse kohta, minu hinnangud võivad Lehiste poolt varem esitatust paratamatult mõneti erineda.

Sarnaselt Lehistega toetan sõnavälte teooriat, mis tugineb seisukohale, et eesti väldete põhidomeen on kõnetakt, st rõhulisest silbist ja sellele järgnevast rõhuta silbist koosnev üksus. Välde on konkreetse sõnavormi leksikaalne omadus, mitte koartikulatiivne nähtus (vt ka Kiparsky, Pajusalu 2002; Pajusalu 2002; Pajusalu jt 2005).

Ühesilbilistes sõnades ei esine eesti keeles vältevastandust, kuigi võib olla üksikhäälikute kestuse vastandusi (nagu saag vs. saak vs. sakk) ja monosüllaabilisi kõnetakte saab seostada kolmandavälteliste kahesilbiliste kõnetaktidega (vt Eek, Meister 2003; 2004, mis esitab ka kokkuvõtte hääliku-, silbi- ja sõnavälte diskussioonist tolleaegse seisuga). Ilma järgneva rõhutu silbita ei suuda eestlane sõna väldet määrata. Seda on näidanud kõik tajukatsed, kus on manipuleeritud silpide pikkustega (vt Lippus jt 2009; Lippus, Pajusalu 2009). Ma ei tea ühtegi katselist kinnitust sellele, et välteerinevused oleks tajutavad ühe silbi piires, küll on aga hulganisti vastupidiseid katsetulemusi (vt ka juba Eek, Meister 1997; 2003; 2004; Lehiste 1997). Ka Hint ise tõdeb: „sõnavormi teine silp on vajalik selleks, et II ja III välte vastandus oleks võimalik", kuid arusaamatuks jääb kohe järgnev väide: „see vastandusvõimalus on rõhulises silbis" (Hint 2015: 172). Kui sama kestusega esimesele silbile lisada küllalt 
pikk teine silp, tajutakse sõna teisevältelisena, kui aga küllalt lühike teine silp, tajutakse sõna kolmandavältelisena.

Läänepoolsest Eestist pärit eestlastel aitab teise ja kolmanda välte erinevust tajuda lisaks erinev põhitooni kontuur, idapoolsete eestlaste jaoks pole see aga üldse oluline, piisab õigest kahe silbi kestussuhtest; silpide kestussuhe on primaarne tunnus ka lääne-eestlaste vältetaju jaoks (Lippus, Pajusalu 2009). Spontaanse eesti keele tegelik hääldus näitab, et mõnigi kord võib teisevältelise sõna esisilp olla pikem kui kolmandavältelises sõnas, ka spontaanse kõne andmeil on eesti väldete püsivaim ja statistiliselt selgelt primaarne akustiline tunnus esimese ja teise silbi kestussuhe (vt Lippus jt 2013).

Lisaks pikkussuhetele on oluline arvestada ka kõnetakti kui intonatsioonilise tervikuga. Eesti keeles ei ole teise ja kolmanda välte põhitooni kontuuri erinevus tajutav ühe silbi raames, see muutub kuuldavaks järgneva rõhutu silbi abil, kus põhitooni kontuur jätkub (Lippus jt 2011). Eriti oluline on see esimese ja teise välte puhul, kuna põhitooni tipp võib nihkuda seal teise silbi algussegi (Asu 2006).

Kõnetaktikesksed on ka eesti väldete uusimad moora- ja optimaalsusteoreetilised fonoloogilised analüüsid (neid esitab Prillop 2013). Silbiteooria põhiprobleemiks jääb nii moora- kui ka optimaalsusteooria seisukohast see, kuidas ikkagi kirjeldada kolme välte vastandust ühe silbi piires. Hindi ( $2001 \mathrm{jm})$ poolt esitatud lahendus, mille kohaselt nii esma- kui ka teisevälteline rõhuline silp on ühemooraline ja ainult kolmandavälteline silp kahemooraline, on vastuolus fonoloogia üldteooriaga, mis eeldab pikkade silpide kahemooralisust. Seda vastuolu on püüdnud lahendada Martin Ehala (2003), postuleerides prosoodilise lisatasandi, kuid ka nii jääb küsitavaks ühelt poolt sidumine empiiriliste foneetiliste andmetega ning teiselt poolt universaalsete fonoloogiliste kitsendustega (vt Prillop 2013: 7-10). Üheks võimalikuks lahenduseks oleks siin teise välte puhul eeldada n-ö seotud teist moorat esimese ja teise silbi piiril (vrd Hayes 1989; Prillop 2011). Sellelgi lähenemisel on oma vastuolud, samas viitab see seni vähe tähelepanu pälvinud nähtusele väldete eristuses: esimese ja teise silbi erinevale seostumisele teise- ja kolmandavältelises kõnetaktis, mis on samas kirjeldatav nii artikulatoorselt kui ka akustiliselt.

Prillop (2013) on esitanud eesti vältevastanduste uue fonoloogilise seletuse, see lähtub René Kageri (1992; 1999: 171-175) kõnetakti prominentsuse teooriast, mille järgi trohheilises kõnetaktis on prominentne esimene moora, jambis viimane moora. Prillop rakendab prominentsete ehk tugevate ja mitteprominentsete ehk nõrkade moorade vastandust eesti väldete kirjeldamisel: esma- ja teisevältelistes sõnades on prominentne (ehk tugev) teise silbi moora, kolmandavältelises sõnas asub prominentne moora esisilbis. Teisevältelise sõna esisilp on kahemooraline, sest see on pikk, kuid nende sõnade esisilbis on teine moora nõrk. Seda toetab ka optimaalsusteoreetiline analüüs (Prillop 2013: 22-25). Seni esitatutest näib see fonoloogiline tõlgendus olevat kõige paremas kooskõlas akustiliste mõõtmiste ja tajutestide andmetega.

Arvestades tõsiasja, et kolmandavältelised silbid saavad esineda pikemas sõnas ühesilbiliste kõnetaktidena, millele võib järgneda teine rõhulise silbiga kõnetakt, jääb üheks võimaluseks kirjeldada neid kui kolmemooralisi, seejuures sidudes aga kolmanda moora kõnetakti lõpupikendusega, et mitte rikkuda silpide kahemooralisuse põhimõtet (esimese ja teise välte puhul toimub lõpupikendus teises silbis ning põhjendab selle pikenemist, vt Kiparsky, Pajusalu 
2002; Pajusalu 2002; Prillop 2013: 14-16). Selline seletus on põhimõtteliselt kooskõlas eelkirjeldatud kõnetakti prominentsuse teooriaga ning seletab lisaks ühesilbiliste sõnade ja kolmandavälteliste kõnetaktide sarnasust.

\section{Kokkuvõtteks: silbi- ja sõnavälte teooria erinevusest}

Hindi esitatud silbiteooria paremus võrreldes häälikuvälte teooriaga on kahtlemata see, et teise ja kolmanda välte erinevust ei tuletata segmentaalsetest erinevustest. Sellisena saab see olla aluseks sõnavälte teooriale, kus üksikhäälikutel ei ole väldet kandvat väärtust. Ometi on silbivälte ja kõnetakti- ehk sõnavälte teoorial põhimõttelisi erinevusi. Hindi enda analüüs (2015: 171172) näitab, et silbivälte põhimõtet rakendades jäävad probleemiks konsonandid esimese ja teise silbi piiril. Geminaadiga sõnade vältevaheldus on aga kirjeldatav sarnaselt pika vokaaliga silpidega sõnadega, kui arvestada kogu kõnetakti, sest sõnade nagu vaga : vaka : vakka esimese ja teise silbi suhted erinevad eri väldetes sarnaselt sõnadega sada : saada : saa:da (siin nagu mujalgi on oluline mitte üksnes silbituumade, vaid silbiriimide pikkuse võrdlus (riim koosneb tuumast ja süllaabilisest koodast); silbi kestuse määramisel ei arvestata silbituumale eelnevaid konsonante).

Sõnaväldet postuleerides ei ole mõttekas vastandada rõhulist ja rõhutut silpi silbivälte teooriast lähtudes, sõnavälte teooria käsitleb neid komplekssete omadustega tervikuna. Nii nagu silbid ei ole üksikhäälikute kimbud, vaid tervikliku struktuuriga fonoloogilised üksused, ei ole ka kõnetaktid lihtsalt silpide järjendid, vaid tervikliku struktuuriga kõrgema tasandi prosoodilised üksused.

Kõnetaktist lähtuva sõnavälte määratlemisel ei saa häälik(uvälde) olla kunagi omaette väärtusega mõiste. Seetõttu ka eesti foneetikas tavapäraste $a d$ hoc terminite kasutus, nagu konsonandikeskne või vokaalikeskne vältemall, saab viidata sõnavältest rääkimisel ainult kõnetakti tüübile, mitte kuidagi aga häälikuvältele. Kõnetakti ehituskivideks on silbid, mis moodustavad terviku kindlate kõnetakti moodustusreeglite alusel.

Kirjutis tugineb Eesti Teadusagentuuri uurimisprojekti IUT2-37 tulemustele.

\section{Kirjandus}

A s u, Eva Liina 2006. Tonal alignment in two varieties of Estonian. - Nordic Prosody. Proceedings of the IX ${ }^{\text {th }}$ Conference, Lund 2004. Toim Gösta Bruce, Merle Horne. Frankfurt am Main: Peter Lang, lk 29-35.

E e k, Arvo, M e ister, Einar 1997. Simple perception experiments on Estonian word prosody: Foot structure vs. segmental quantity. - Estonian Prosody. Papers from a Symposium: Proceedings of the International Symposium on Estonian Prosody, Tallinn, Estonia, October 29-30, 1996. Toim Ilse Lehiste, Jaan Ross. Tallinn: Institute of Estonian Language, lk 71-99.

E e k, Arvo, M e i s t e r, Einar 2003. Foneetilisi katseid ja arutlusi kvantiteedi alalt (I). Häälikukestusi muutvad kontekstid ja välde. - Keel ja Kirjandus, nr 11, lk 815-837; nr 12, lk 904-918. 
E e k, Arvo, M e i s t e r, Einar 2004. Foneetilisi katseid ja arutlusi kvantiteedi alalt (II): Takt, silp ja välde. - Keel ja Kirjandus, nr 4, lk 251-271; nr 5, lk 336-357.

$\mathrm{E}$ h a l a, Martin 2003. Estonian quantity: Implications for moraic theory. - Generative Approaches to Finnic and Saamic Linguistics. (CSLI Lecture Notes 148.) Toim Diane Nelson, Satu Manninen. Stanford: CSLI, lk 51-80.

$\mathrm{H}$ a y e s, Bruce 1989. Compensatory lengthening in moraic phonology. - Linguistic Inquiry, kd 20, nr 2, lk 253-306.

H in t, Mati 2001. Prosoodiaväitlustes läbimurdeta. - Keel ja Kirjandus, nr 3, lk 164-172; nr 4, lk 252-258; nr 5, lk 324-339.

H i n t, Mati 2015. Kolme häälikuvälte eksituse mehaanika. - Keel ja Kirjandus, nr 3, lk 163-177.

K a g e r, René 1992. Shapes of the generalized trochee. - The Proceedings of the Eleventh West Coast Conference on Formal Linguistics. Toim Jonathan Mead. Chicago: CSLI, lk 298-312.

K a g e r, René 1999. Optimality Theory. Cambridge: Cambridge University Press. $\mathrm{Ki}$ p a r s ky, Paul, P a j u a l u, Karl 2002. Seto vowel harmony and the typology of disharmony. Ms. www.stanford.edu/ kiparsky/Papers/seto.pdf (23. III 2015).

L e h i s te, Ilse 1997. Search for phonetic correlates in Estonian prosody. - Estonian Prosody. Papers from a Symposium: Proceedings of the International Symposium on Estonian Prosody, Tallinn, Estonia, October 29-30, 1996. Toim Ilse Lehiste, Jaan Ross. Tallinn: Institute of Estonian Language, lk 11-35.

L e h i s t e, Ilse, P a j u s a l u, Karl 2010. Experimental study of prosody in FinnoUgric languages. - Congressus XI Internationalis Fenno-Ugristarum Piliscsaba 9.-14. VIII 2010. Pars I. Orationes plenariae. Piliscsaba: Reguly Társaság, lk 225-245.

Li p pus, Pärtel 2011. The Acoustic Features and Perception of the Estonian Quantity System. (Dissertationes philologiae Estonicae Universitas Tartuensis 29.) Tartu: Tartu Ülikooli Kirjastus.

L i p p u s, Pärtel, Paj u s a l u, Karl 2009. Regional variation in the perception of Estonian quantity. - Nordic Prosody. Proceedings of the $\mathrm{X}^{\text {th }}$ Conference, Helsinki 2008. Toim Martti Vainio, Reijo Aulanko, Olli Aaltonen. Frankfurt am Main: Peter Lang Verlag, lk 151-157.

Li p p u s, Pärtel, Paju s a l u, Karl, Allik, Jüri 2009. The tonal component of Estonian quantity in native and non-native perception. - Journal of Phonetics, kd 37, nr 4, lk 388-396.

Lippus, Pärtel, Pajus a lu, Karl, Allik, Jüri 2011. The role of pitch cue in the perception of the Estonian long quantity. - Prosodic Categories: Production, Perception and Comprehension. (Studies in Natural Language and Linguistic Theory 82.) Toim Sónia Frota, Gorka Elordieta, Pilar Prieto. Dordrecht-Heidelberg-London-New York: Springer, lk 231-242.

Li p p us, Pärtel, As u, Eva Liina, Ter a s, Pire, Tu is k, Tuuli 2013. Quantityrelated variation of duration, pitch and vowel quality in spontaneous Estonian.Journal of Phonetics, kd 41, nr 1, lk 17-28.

P aju s a l u, Karl 2002. Varieerumisreeglid ja optimaalsusteooria. - Teoreetiline keeleteadus Eestis. (Tartu Ülikooli üldkeeleteaduse õppetooli toimetised 4.) Toim Renate Pajusalu, Ilona Tragel, Tiit Hennoste, Haldur Õim. Tartu: Tartu Ülikooli Kirjastus, lk 195-208.

Paju s a lu, Karl 2008. Eesti fonoloogia teisenemised Keeles ja Kirjanduses. Keel ja Kirjandus, nr 1, lk 16-27. 
P a ju s a l u, Karl 2014. Eesti keele sõnaprosoodia lõuna-läänemeresoome taustal. - Keel ja Kirjandus, nr 8-9, lk 575-589.

P a j u s a l u, Karl, Help, Toomas, Li p p u s, Pärtel, Ni i t, Ellen, T e r a s, Pire, Viits o, Tiit-Rein 2005. On the temporal structure of Estonian secondarystressed feet. - Linguistica Uralica, kd XLI, nr 2, lk 98-106.

P rill o p, Külli 2011. Optimaalsusteoreetiline käsitlus eesti keele fonoloogilisest kujunemisest. (Dissertationes philologiae Estonicae Universitas Tartuensis 28.) Tartu: Tartu Ülikooli Kirjastus.

P rill o p, Külli 2013. Feet, syllables, moras and the Estonian quantity system. Linguistica Uralica, kd XLIX, nr 1, lk 1-29.

\section{On the nature of Estonian quantity system}

Keywords: Estonian language, phonetics, phonology, word prosody, quantity degrees

The article surveys the recent acoustic and perceptual studies of Estonian phonetic quantity and introduces some new phonological interpretations of the ternary opposition of the Estonian quantity degrees. Answering to Mati Hint's (2015) criticism, which is based on a theory of syllable quantity, the Estonian opposition of three quantity degrees is explained as a property of minimally disyllabic metrical feet. Acoustically as well as perceptually, Estonian quantity degrees are a complex phenomenon depending on durational differences, pitch contour, intensity, sound quality, and the way of binding of the first and second syllables (cf. Lippus et al. 2013). The article points out that those phonological analyses of Estonian quantity degrees, which examine the quantity within a foot (e.g. Prillop 2013), are consistent with recent acoustic and perceptual results.

Karl Pajusalu (b. 1963), PhD, Member of the Estonian Academy of Sciences, University of Tartu, Professor of History and Dialects of the Estonian Language, karl.pajusalu@ut.ee 